\title{
OBSERVATIONS ON DIAPHRAGMATIC MOVEMENT IN SOME NEUROLOGICAL DISORDERS
}

\author{
BY \\ P. K. ROBINSON, W. H. MOSBERG, Jnr., and R. C. W. LOWE \\ From the Neurological Research Unit of the Medical Research Council, \\ National Hospital, Queen Square, London
}

The object of these investigations was to find out whether the movements of the diaphragm are affected in certain neurological disorders, and if possible the nature of these changes. The literature contains various opinions about respiratory movements in neurological lesions but most of these statements have been concerned with chest movements. In this study the method described by Gilson (1949) for recording diaphragmatic movements was applied to patients with neuro$\log$ cal disease.

\section{Methods and Material}

The apparatus described by Gilson (1949) consisted of a tracking device attached to a fluoroscopic screen, which was connected by means of a Bowden cable to a pen writing on a revolving drum. Movement of the dome of the diaphragm as seen on the screen was recorded by hand, while at the same time a spirometer tracing was made. In our study the apparatus was modified by having two tracking devices so that the movements of the right and left domes of the diaphragm might be recorded simultaneously. In the study by Gilson and Wade (1950) and in our records corrections for exaggeration of the movement due to distance from the source of the ray were made. Since our recording pens differed somewhat from those employed by these observers, calibration and repeated correction were carried out.

A length of corrugated respirator tubing was attached to each side of the upper chest in order to record chest expansion. Each piece was of sufficient length to encircle half the chest at the level of the sternomanubrial junction. The anterior and the posterior ends of the tubes were joined by non-stretchable cord which was strapped to the skin in the midline over the sternum and spine. The ends of each tube were also strapped to the chest and supported by cords over each shoulder. The tubing was sealed at one end and at the other communicated with a Palmer's float recorder by means of pressure tubing. In this way five records were made synchronously on the same paper.
The following routine was adopted :

A period was spent in accustoming the patient to breathing into the spirometer. With the patient in position, unless otherwise stated, screening was done with the subject in the standing position facing the observer. The fluorescent screen was adjusted so that the central axis of the $x$ rays was at the same horizontal level as the summit of the left dome of the diaphragm at its highest point during quiet respiration. The central axis was marked by a piece of piano-wire stretched across the middle of the back of the screen. The vertical distance was measured between the peaks of the two domes when they were at their highest point $\stackrel{\circ}{\square}$ during quiet breathing. A record was then taken with each of the two observers following the movements of one dome of the diaphragm with the tracking device mentioned above.

The following types of record were made in sequence with a third observer giving appropriate instructions to the subject : (a) quiet respiration ; $(b)$ vital capacity? (repeated at least once) ; (c) voluntary overbreathing * ; (d) involuntary overbreathing (produced by shortcircuiting the soda-lime canister of the spirometer) ${ }^{*}$; (e) interrupted deep inspiration and expiration. After a period of normal quiet respiration the subject was instructed to inspire deeply. Before inspiration was completed he was commanded suddenly to hold his breath; then after a pause of approximately three seconds he was told to complete the inspiration. The subsequent expiration was stopped when the subject had expired as much air as he had inspired following the halt during inspiration. This point was easily determined from the spirometer tracing. Normal breathing was then resumed. Following a period of normal quiet respiration the reverse was done ; that is, the subject was instructed to carry out a forced expiration, and this was interrupted in a similar manner.

The vertical diaphragmatic excursion as recorded on the tracings is given in millimetres in the tables. The figures for quiet breathing presented in the text are the average of ten such measurements, and those for vital capacity are in most cases obtained by measurement of one such breath.

$$
\text { *Not done in all cases. }
$$


Tracings were obtained from 14 healthy males (aged 25 to 35 years) for a control group. The abnormal cases $\dagger$ were chosen to represent lesions at various sites within the nervous system, the nature of the underlying pathology being a secondary consideration. There were 14 cases of hemiplegia, eight right-sided and six left-sided. The remaining cases included a variety of disorders, some unilateral such as Parkinson's syndrome, and others bilateral, at various "levels" in the neuromuscular system governing respiration. Unless otherwise stated, these patients were free from disease of the lung or pleura.

†The following are the case numbers of the patients of the National Hospital, Queen Square, investigated in this series: 1363, 7529, Hospital, Queen Square, investigated in this series : 1363, 7529,
$21240,7236,21951,16631,2566,2374,21172,17844,23287,22331$ $21240,7236,21951,16631,2566,2374,21172,17844,23287,22331$,

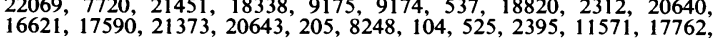
$15914,11052,13427,18077,18078,20069,7712,21191,19497,1921$, $461,20278$.

Two patients from the Military Hospital for Head Injuries, Oxford, with case numbers 19544 and 9269 were examined, as well as four patients from the Star and Garter Home for Disabled Sailors and

Soldiers, Richmond.

\section{Results}

Special attention is given to the cases with hemiplegia, myasthenia gravis, palatal myoclonus, phrenic palsy, and to lesions of the cervical spinal cord.

Healthy Subjects.-Although this investigation was not intended as a study of the physiology of normal respiration, certain observations came to light in this control group which will be briefly presented. In all cases during normal breathing the diaphragmatic excursion on the left was greater than that on the right. In the tracings of vital capacity it was found that the difference between excursions of right and left diaphragm was reduced (Table I).

A typical tracing in a healthy subject (Fig. 1) demonstrates the relative roles of chest musculature and diaphragm in respiration. Interrupted deep

TABLE I

MOVEMENT OF THE DIAPHRAGM AND CHEST MUSCLES IN NORMAL CONTROL GROUP

\begin{tabular}{|c|c|c|c|c|c|c|c|c|c|c|}
\hline \multirow{3}{*}{ Name } & \multicolumn{5}{|c|}{$\begin{array}{l}\text { Quiet Breathing } \\
\text { (Tidal Movement) }\end{array}$} & \multicolumn{5}{|c|}{$\begin{array}{l}\text { Forced Breathing } \\
\text { (Vital Capacity) }\end{array}$} \\
\hline & \multicolumn{3}{|c|}{ Diaphragm Movement } & \multicolumn{2}{|c|}{ Chest expansion } & \multicolumn{3}{|c|}{ Diaphragm Movement } & \multicolumn{2}{|c|}{ Chest Expansion } \\
\hline & Right & Left & Difference* & Right & Left & Right & Left & Difference* & Right & Left \\
\hline $\mathrm{Li}$ & $11 \dagger$ & 19 & +8 & 2 & 2 & 62 & 61 & -1 & 23 & 22 \\
\hline McL & 19 & 29 & +10 & 2 & 2 & 54 & 60 & +6 & -27 & 25 \\
\hline $\mathrm{Cl}$ & 21 & 26 & +5 & 4 & 5 & - & - & - & - & - \\
\hline Mi & 16 & 27 & +11 & - & - & 75 & 83 & +8 & - & - \\
\hline $\mathrm{Sp}$ & 21 & 24 & +3 & 5 & 4 & 75 & 78 & +3 & 30 & 30 \\
\hline $\mathrm{Le}$ & 18 & 28 & +10 & - & - & 47 & 63 & +16 & - & - \\
\hline $\mathrm{Ga}$ & 15 & 22 & +7 & 6 & 5 & 70 & 70 & 0 & 25 & 23 \\
\hline $\mathrm{Pa}$ & 19 & 25 & +6 & $3 \cdot 5$ & 3 & 65 & 69 & +4 & 25 & 25 \\
\hline Ma & 19 & 22 & +3 & $1 \cdot 5$ & 2 & 80 & 86 & +6 & 19 & 20 \\
\hline $\mathrm{Ge}$ & 12 & 19 & +7 & - & - & 37 & 37 & 0 & - & - \\
\hline $\mathrm{Ba}$ & 13 & 20 & +7 & - & - & 60 & 53 & -7 & - & - \\
\hline Mo & 15 & 21 & +6 & - & - & 62 & 54 & -8 & - & - \\
\hline An & 16 & 22 & +6 & - & - & 56 & 58 & +2 & - & - \\
\hline $\mathrm{Sa}$ & 17 & 19 & +2 & - & - & 73 & 74 & +1 & - & - \\
\hline Average & 17 & 23 & +6 & 3 & 3 & 63 & 65 & +2 & 21 & 21 \\
\hline
\end{tabular}

*The difference between the two sides is given as a positive or negative figure with reference to the figure for the right side.

$\dagger$ The figures represent in millimetres the vertical range of movement of the diaphragm and the increase in circumference of the half chest. 


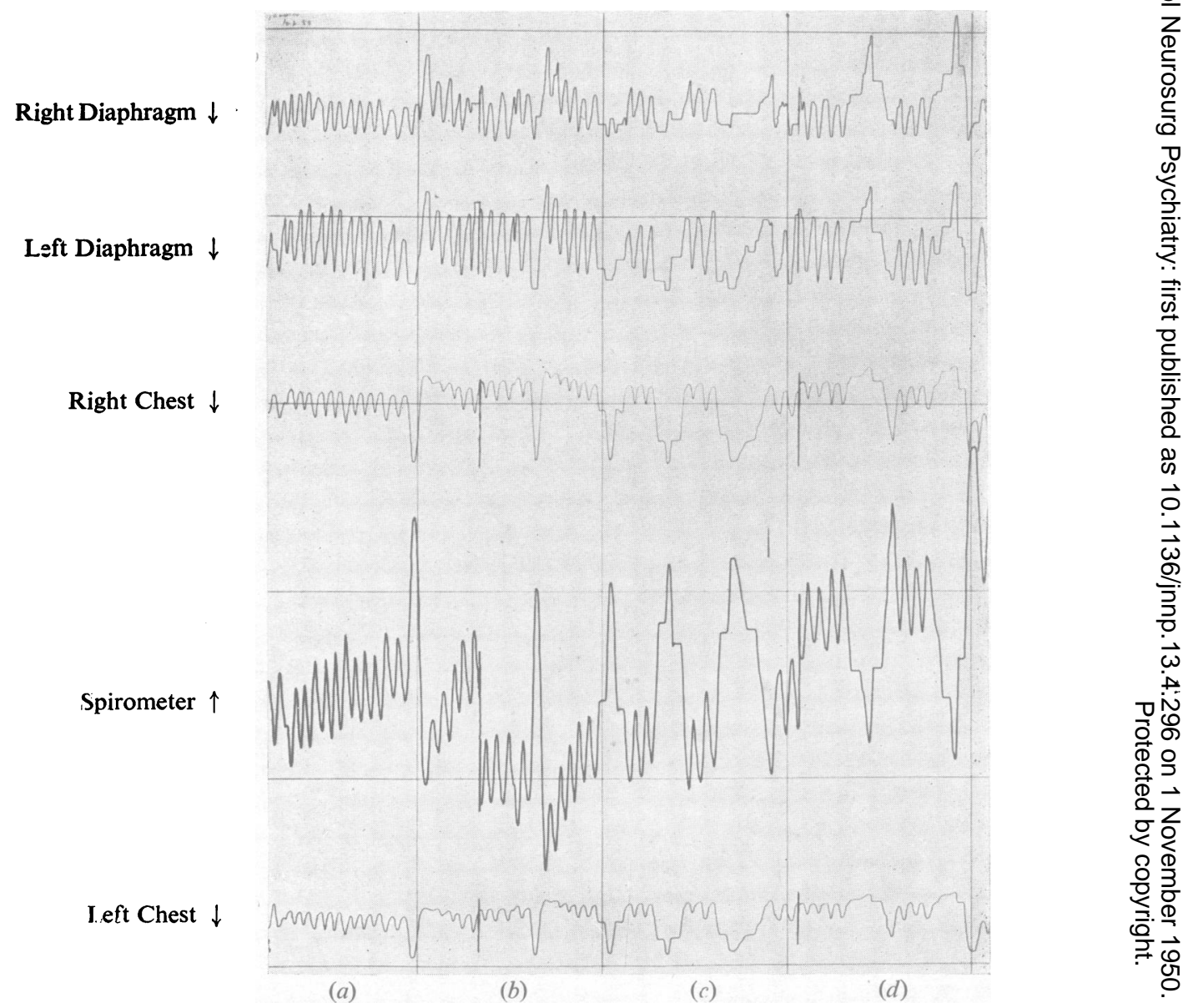

FIG. 1.-Record of spirometry and chest and diaphragmatic movements in a healthy subject showing : (a) Normal quiet respiration, (b) vital capacity, (c) interrupted deep inspiration, and (d) interrupted deep expiration. The arrows point in the direction taken by the pens during inspiration.

The vertical line of each square represents $2,300 \mathrm{ml}$. on the spirometer tracing.

inspirations and expirations revealed the movement of the diaphragm in successive phases of the respiratory cycle during forced respiration. The interruptions of the forced breath beginning with inspiration (Fig. 1c) occurred at such a time that equal amounts of air had been inspired and expired immediately before and after the inspiratory limit. A study of the records shows that the extra air flow of forced inspiration appears to be accomplished mainly by costal movement, but during subsequent expiration movement of the diaphragm predominates. A similar analysis of the forced breaths starting with expiration (Fig. 1d) shows that the expiratory phase appears to be accomplished mainly by diaphragmatic movement. At the onset of inspiration, following the expiratory limit, there was usually a similar preponderance of diaphragmatic over costal movement but the reverse was found in two of our normal controls.

Hemiplegia.-The average figures for diaphragmatic excursion in quiet and forced breathing in Cases 1 to 14 are presented in Table II. The danger of inducing an epileptic fit made it inadvisable to obtain records of overbreathing in many of these subjects.

Our finding that in normal subjects the left diaphragmatic excursion was consistently greater than that on the right modified any interpretation of disparity between the two sides in cases of hemiplegia. There was no significant difference between the records of patients with right hemiplegia and those of healthy subjects in quiet breathing, but in the group of left hemiplegics 
TABLE II

MOVEMENT OF THE DIAPHRAGM AND CHEST MUSCLES IN HEMIPLEGIA

\begin{tabular}{|c|c|c|c|c|c|c|c|c|c|c|c|c|c|}
\hline \multirow{4}{*}{$\begin{array}{c}\text { Case } \\
\text { No. }\end{array}$} & \multirow{4}{*}{$\begin{array}{c}\text { Age } \\
\text { (years) }\end{array}$} & \multirow{4}{*}{$\begin{array}{c}\text { Site of } \\
\text { Pathology }\end{array}$} & \multirow{4}{*}{$\begin{array}{l}\text { Nature of } \\
\text { Pathology }\end{array}$} & \multicolumn{5}{|c|}{ Quiet Breathing } & \multicolumn{5}{|c|}{ Forced Breathing } \\
\hline & & & & \multicolumn{3}{|c|}{$\begin{array}{l}\text { Diaphragm } \\
\text { Movement }\end{array}$} & \multicolumn{2}{|c|}{$\begin{array}{l}\text { Chest } \\
\text { Expan- } \\
\text { sion }\end{array}$} & \multicolumn{3}{|c|}{$\begin{array}{l}\text { Diaphragm } \\
\text { Movement }\end{array}$} & \multicolumn{2}{|c|}{$\begin{array}{l}\text { Chest } \\
\text { Expan- } \\
\text { sion }\end{array}$} \\
\hline & & & & Rt. & Lft. & Diff. + & Rt. & Lft. & Rt. & Lft. & Diff. + & Rt. & Lft. \\
\hline & & & & \multicolumn{10}{|c|}{ Right Hemiplegia } \\
\hline 1 & 44 & Left frontal & $\begin{array}{l}\text { Grade II (Kernohan } \\
\text { and oth:rs, 1949) } \\
\text { astrocytoma }\end{array}$ & $16 \dagger$ & 24 & +8 & 5 & 9 & 28 & 35 & +7 & 13 & 15 \\
\hline 2 & 70 & Left fronto-temporal & Thrombosis & 16 & 26 & +10 & 1 & 2 & 23 & 40 & +17 & 5 & 8 \\
\hline 3 & 73 & $\begin{array}{l}\text { Left fronto-parieto } \\
\text { occipital }\end{array}$ & Thrombosis & 21 & 33 & +12 & 2 & 2 & 41 & 53 & +12 & 17 & 18 \\
\hline 4 & 41 & Brain stem & Thrombosis & 16 & 20 & +4 & - & - & 24 & 29 & +5 & - & - \\
\hline 5 & 18 & $\begin{array}{l}\text { Left cerebral hemi- } \\
\text { sphere }\end{array}$ & $\begin{array}{l}\text { Cortical thrombo- } \\
\text { phlebitis }\end{array}$ & 9 & 11 & +2 & 5 & 4 & 30 & 23 & -7 & 20 & 16 \\
\hline \multirow[t]{3}{*}{6} & 61 & Left frontal & Thrombosis & 10 & 14 & +4 & 1 & 3 & 11 & 20 & +9 & 10 & 13 \\
\hline & & Average & $\cdots$ & 15 & 21 & +6 & 3 & 4 & 26 & 33 & +7 & 13 & 14 \\
\hline & & & & \multicolumn{10}{|c|}{ Left Hemiplegia } \\
\hline $9 *$ & 47 & $\begin{array}{l}\text { Right posterior } \\
\text { parietal }\end{array}$ & $\begin{array}{l}\text { Grade III (Kernohan } \\
\text { and others, 1949) } \\
\text { astrocytoma }\end{array}$ & 17 & 15 & -2 & - & - & 29 & 36 & +7 & - & - \\
\hline 10 & 31 & Right parietal & Gunshot wound & 18 & 19 & +1 & - & - & 75 & 69 & -6 & - & - \\
\hline 11 & 36 & $\begin{array}{l}\text { Right posterior } \\
\text { parietal }\end{array}$ & Gunshot wound & 13 & 12 & -1 & 3 & $1 \cdot 5$ & 47 & 44 & -3 & 28 & 21 \\
\hline 12 & 25 & $\begin{array}{l}\text { Right temporo- } \\
\text { parietal }\end{array}$ & Gunshot wound & 16 & 24 & +8 & 4 & 4 & 54 & 60 & +6 & 26 & 22 \\
\hline 13 & 50 & Right fronto-parietal & $\begin{array}{l}\text { Grade III (Kernohan } \\
\text { and othzrs, 1949) } \\
\text { astrocytoma }\end{array}$ & 25 & 23 & -2 & - & - & 73 & 63 & -10 & 一 & - \\
\hline \multirow[t]{3}{*}{14} & 16 & Right fronto-parietal & $\begin{array}{c}\text { cortical venous } \\
\text { thrombophlebitis }\end{array}$ & 13 & 12 & -1 & - & - & 26 & 31 & +5 & - & - \\
\hline & & \multicolumn{2}{|l|}{ Average } & 17 & $17 \cdot 5$ & +0.5 & $3 \cdot 5$ & $2 \cdot 5$ & 51 & $50 \cdot 5$ & -0.5 & 27 & $21 \cdot 5$ \\
\hline & & & & \multicolumn{10}{|c|}{ Infantile Hemiplegia } \\
\hline 7 & 32 & $\begin{array}{l}\text { Left cerebral hemi- } \\
\text { sphere }\end{array}$ & Infantile hemiplegia & 12 & 18 & +6 & - & - & 38 & 39 & +1 & - & - \\
\hline 8 & 35 & $\begin{array}{l}\text { Left cerebral hemi- } \\
\text { sphere }\end{array}$ & Infantile hemiplegia & 13 & 16 & +3 & - & - & 38 & 26 & -12 & - & - \\
\hline
\end{tabular}

*Patient examined supine.

†The figures represent in millimetres the vertical range of movement of the diaphragm and the increase in circumference of the half chest. $\ddagger$ The difference between the two sides is given as a positive or negative figure, with reference to the figure for the right side. 
studied the average difference between left and right diaphragm movement during quiet breathing was less than in healthy subjects. Whereas in healthy subjects the disparity in movement between the left and right diaphragm appeared to lessen markedly in the taking of a vital capacity, such was not the case in the hemiplegic subjects in this group. It may be seen from Table II that in the measurements of the diaphragmatic movement during forced respiration the disparity between the two sides of the diaphragm remained approximately the same as occurs in quiet breathing. From this it is clear that it is during forced breathing that diminished movement of the diaphragm is most likely to be apparent. The two cases of infantile hemiplegia did not significantly deviate from normal, and these results are given separately in Table II. The records obtained from the normal controls showed that the chest expansion was equal on both sides. The figures for hemiplegia indicate less movement of the paralysed side in both right and left hemiplegia, during quiet and forced breathing (Fig. 2). The disparity was more apparent during the latter and was in agreement with clinical observation and palpation of the chest wall.

Myasthenia Gravis.-In this group quiet breathing and vital capacity were recorded before and after an intravenous injection (1 mg.) of prostigmine and $(1 / 100$ gr.) atropine. Special records which would have permitted analysis of different phases of the respiratory cycle as were carried out in our normal controls were found to be beyond the capacity of this group of patients. Cases 16 to 18 (Table III) which had not had the thymus gland removed showed a degree of diaphragmatic movement which was smaller than the average healthy subject and which varied irregularly from breath to breath, but in the three cases (Cases 19 to 21) which had undergone thymectomy no such abnormalities were seen. After prostigmine the amplitude increased and the irregularity diminished (Fig. 3). Although diaphragmatic movement in tidal breathing and during the recording of a vital capacity showed very low values in these three non-thymectomized cases, it approached our normal values in the three patients who had undergone thymectomy. In two of the latter, nevertheless, there was an increase in these diaphragmatic movements after $1 \mathrm{mg}$. of prostigmine intravenously. Case 16 was the only patient to make spontaneous complaint of dyspnoea and, before receiving a prostigmine injection, was unable to take a deep breath.

Palatal Myoclonus.-Both of the cases studied in this group have been clinically reported. Case 22, reported by Wilson and Walshe (1950), had bilateral
Right Diaphragm $\downarrow$

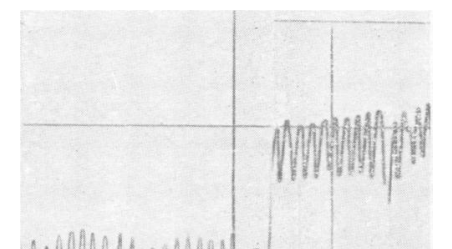

Left Diaphragm $\downarrow$

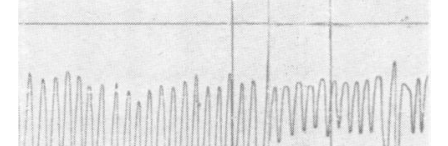

Right Chest $\downarrow$
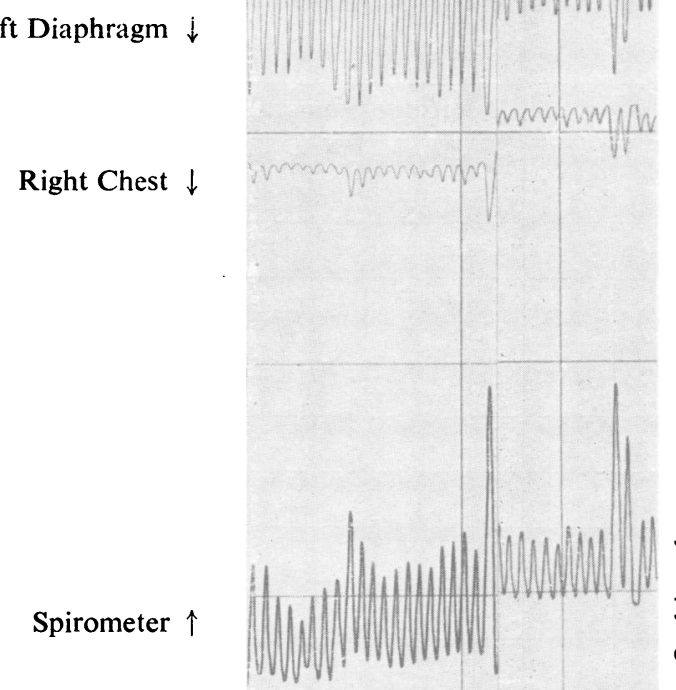

Left Chest $\downarrow$

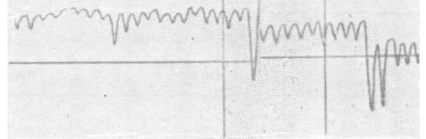

(a)

(b)

FIG. 2.-Records from two cases of hemiplegia in which diaphragmatic movement was diminished on the paralysed side. (a) Case 3 , right hemiplegia ; (b) Case 9, left hemiplegia. The diminution of diaphragmatic movement may more easily be appreciated by comparing these records with Fig. 1 .

The arrows point in the direction taken by the pens during inspiration.

The vertical line of each square represents 2,300 $\mathrm{ml}$. on the spirometer tracing.

rhythmic myoclonus of palate, pharynx, and larynx (180 per minute); and Case 23, reported by Shy and Carmichael (1949), had unilateral rhythmic myoclonus of palate, pharynx, larynx, face, and arm. Neither of these cases exhibited myoclonus of the diaphragm and no abnormality of the excursion was demonstrated. 
TABLE III

MOVEMENT OF THE DIAPHRAGM AND AIR EXCHANGE IN PATIENTS WITH MYASTHENIA GRAVIS

\begin{tabular}{|c|c|c|c|c|c|c|c|c|c|c|c|c|c|c|c|}
\hline \multirow{4}{*}{$\begin{array}{l}\text { Case } \\
\text { No. }\end{array}$} & \multirow{4}{*}{$\begin{array}{l}\text { Age } \\
\text { (years) }\end{array}$} & \multirow{4}{*}{$\begin{array}{l}\text { Years } \\
\text { since } \\
\text { Thymec- } \\
\text { tomy }\end{array}$} & \multirow{4}{*}{$\begin{array}{l}\text { Present } \\
\text { Daily } \\
\text { Dose of } \\
\text { Prostig- } \\
\text { mine } \\
\text { (mg.) }\end{array}$} & \multicolumn{8}{|c|}{$\underset{(\mathrm{mm} .)}{\text { Diaphragm Movement }}$} & \multicolumn{4}{|c|}{$\begin{array}{l}\text { Air Exchange } \\
(\mathrm{ml} .)\end{array}$} \\
\hline & & & & \multicolumn{4}{|c|}{ Quiet Breathing } & \multicolumn{4}{|c|}{ Vital Capacity } & \multicolumn{2}{|c|}{ Tidal Air } & \multicolumn{2}{|c|}{ Vital Capacity } \\
\hline & & & & \multicolumn{2}{|c|}{$\begin{array}{c}\text { Before } \\
\text { Prostig- } \\
\text { mine }\end{array}$} & \multicolumn{2}{|c|}{$\begin{array}{l}\text { After } \\
\text { Prostig- } \\
\text { mine }\end{array}$} & \multicolumn{2}{|c|}{$\begin{array}{c}\text { Before } \\
\text { Prostig- } \\
\text { mine }\end{array}$} & \multicolumn{2}{|c|}{$\begin{array}{l}\text { After } \\
\text { Prostig- } \\
\text { mine }\end{array}$} & \multirow{2}{*}{$\begin{array}{c}\text { Before } \\
\text { Prostig- } \\
\text { mine }\end{array}$} & \multirow{2}{*}{$\begin{array}{l}\text { After } \\
\text { Prostig- } \\
\text { mine }\end{array}$} & \multirow{2}{*}{$\begin{array}{l}\text { Before } \\
\text { Prostig- } \\
\text { mine }\end{array}$} & \multirow{2}{*}{$\begin{array}{l}\text { After } \\
\text { Prostig- } \\
\text { mine }\end{array}$} \\
\hline & & & & Right & Left & Right & Left & Right & Left & Right & Left & & & & \\
\hline 16 & 39 & $\begin{array}{c}\text { Not } \\
\text { per- } \\
\text { formed }\end{array}$ & 300 to 360 & 5 & 6 & 7 & 7 & \multicolumn{2}{|c|}{$\begin{array}{l}\text { Unable to } \\
\text { perform }\end{array}$} & 20 & 12 & 340 & 410 & 340 & 1160 \\
\hline 17 & 41 & $\begin{array}{c}\text { Not } \\
\text { per- } \\
\text { formed }\end{array}$ & 45 & 9 & 7 & 8 & 15 & 15 & 15 & - & - & 430 & 550 & 1190 & - \\
\hline 18 & 21 & $\begin{array}{c}\text { Not } \\
\text { per- } \\
\text { formed }\end{array}$ & 460 & \multicolumn{6}{|c|}{ No measurements possible: } & \multicolumn{3}{|c|}{ record very irregular } & & & \\
\hline 19 & 41 & 8 & 30 & 14 & 17 & 18 & 23 & 37 & 35 & 50 & 49 & 950 & 1150 & 3250 & 3250 \\
\hline $20^{*}$ & 35 & 8 & 180 to 210 & 29 & 28 & 44 & 38 & 67 & 50 & 72 & 58 & 840 & 960 & 1890 & 2390 \\
\hline 21 & 33 & 4 & 300 & 14 & 15 & 17 & 13 & 53 & 59 & 54 & 52 & 700 & 700 & 3100 & 2800 \\
\hline
\end{tabular}

*Post-operative left sided pneumonia.

TABLE IV

MOVEMENT OF DIAPHRAGM IN LESIONS AFFECTING THE CERVICAL CORD

\begin{tabular}{|c|c|c|c|c|c|c|c|}
\hline \multirow{3}{*}{$\begin{array}{l}\text { Case } \\
\text { No. }\end{array}$} & \multirow{3}{*}{$\begin{array}{c}\text { Age } \\
\text { (years) }\end{array}$} & \multirow{3}{*}{$\begin{array}{l}\text { Clinical } \\
\text { Diagnosis }\end{array}$} & \multirow{3}{*}{$\begin{array}{l}\text { Evidence of Involvement } \\
\text { of Cervical Cord }\end{array}$} & \multicolumn{4}{|c|}{$\begin{array}{l}\text { Diaphragm Movement } \\
(\mathrm{mm} .)\end{array}$} \\
\hline & & & & \multicolumn{2}{|c|}{ Quiet Breathing } & \multicolumn{2}{|c|}{ Vital Capacity } \\
\hline & & & & Right & Left & Right & Left \\
\hline 24 & 44 & $\begin{array}{l}\text { Amyotrophic lateral } \\
\text { sclerosis }\end{array}$ & $\begin{array}{l}\text { Severe wasting and weakness of } \\
\text { shoulder girdles and upper arms }\end{array}$ & 8 & 11 & 17 & 20 \\
\hline 25 & 27 & $\begin{array}{l}\text { Amyotrophic lateral } \\
\text { sclerosis }\end{array}$ & $\begin{array}{l}\text { Weakness of neck flexors and of } \\
\text { shoulder girdles with wasting }\end{array}$ & 9 & 12 & 21 & 21 \\
\hline 26 & 46 & $\begin{array}{l}\text { Disseminated } \\
\text { sclerosis }\end{array}$ & $\begin{array}{l}\text { Weakness of right arm, para- } \\
\text { paresis, hypalgesia below left } \\
\text { C3 segment }\end{array}$ & 11 & 17 & 31 & 45 \\
\hline $27^{*}$ & 27 & $\begin{array}{l}\text { Syphilitic meningo- } \\
\text { myelitis }\end{array}$ & $\begin{array}{l}\text { Profound flaccid weakness of both } \\
\text { arms ; wasting of shoulder } \\
\text { girdles; hypalgesia and hypaes- } \\
\text { thesia below right C2 and left } \\
\text { C4 segments }\end{array}$ & 3 & 8 & 3 & 11 \\
\hline $28 \dagger$ & 26 & $\begin{array}{l}\text { Fracture dislocation } \\
\text { of fifth cervical } \\
\text { vertebra }\end{array}$ & $\begin{array}{l}\text { Quadriplegia within } 24 \text { hours of } \\
\text { injury. Transverse spinal syn- } \\
\text { drome C6 with spastic para- } \\
\text { plegia }\end{array}$ & 21 & 15 & 53 & 40 \\
\hline
\end{tabular}


Lesions of the Cervical Spinal Cord and Phrenic Nerve.-It was thought that cases with lesions in the neighbourhood of the fourth and fifth cervical segments might show evidence of partial paresis of the diaphragm on one or both sides according to the side most severely affected. Five such cases were studied (Table IV). The two cases of amyotrophic lateral sclerosis (Cases 24 and 25) showed clinical evidence of bilateral involvement of the fifth cervical segment and probably of the fourth also. The diaphragmatic excursion, as measured from the records taken during quiet and forced breathing, showed values below the range of normal. This poverty of movement was particularly noticeable during an attempt to record the vital capacity, which was of itself much reduced. In the case of disseminated sclerosis affecting mainly the cervical enlargement (Case 26), although there was a predominantly right-sided cord lesion, there was no clinical evidence of root involvement and, as might be expected, no diminution of diaphragmatic movement on the affected side. Having recovered from her most serious respiratory difficulties, the patient with syphilitic meningo-myelitis (Case 27) was examined in the sitting position. The record of her diaphragmatic movement showed its excursion to be very small indeed, and the right side was more severely affected, which was in keeping with the physical signs associated with the fifth segment. The physical signs in Case 28, paraplegic as a result of a fracture dislocation at $\mathrm{C5}$, were more marked on the left side and the records (which were made with the patient lying supine) revealed more movement of the right diaphragm. Furthermore the movement of the left diaphragm in this case was less than that of any of the healthy controls. The patient with idiopathic phrenic palsy (Case 29) showed the well-known paradoxical movement of the paralysed dome associated with phrenic palsy and a graphic representation was easily obtained, the excursion on that side being less than normal and in the opposite direction (Fig. 4).

Miscellaneous.-Five patients with Parkinson's syndrome involving one side predominantly and causing tremor and very little increase in tone were examined. No poverty of movement was demonstrated and no tremor of the diaphragm on the side of the body affected by tremor.

Three patients with traumatic paraplegia as the result of a lesion in the upper thoracic region (T3-T5) were examined in the supine position. The excursion of the diaphragm in quiet and deep breathing was within normal limits.

Two cases of Huntington's chorea exhibited grossly irregular respiratory rhythm and diaphragm

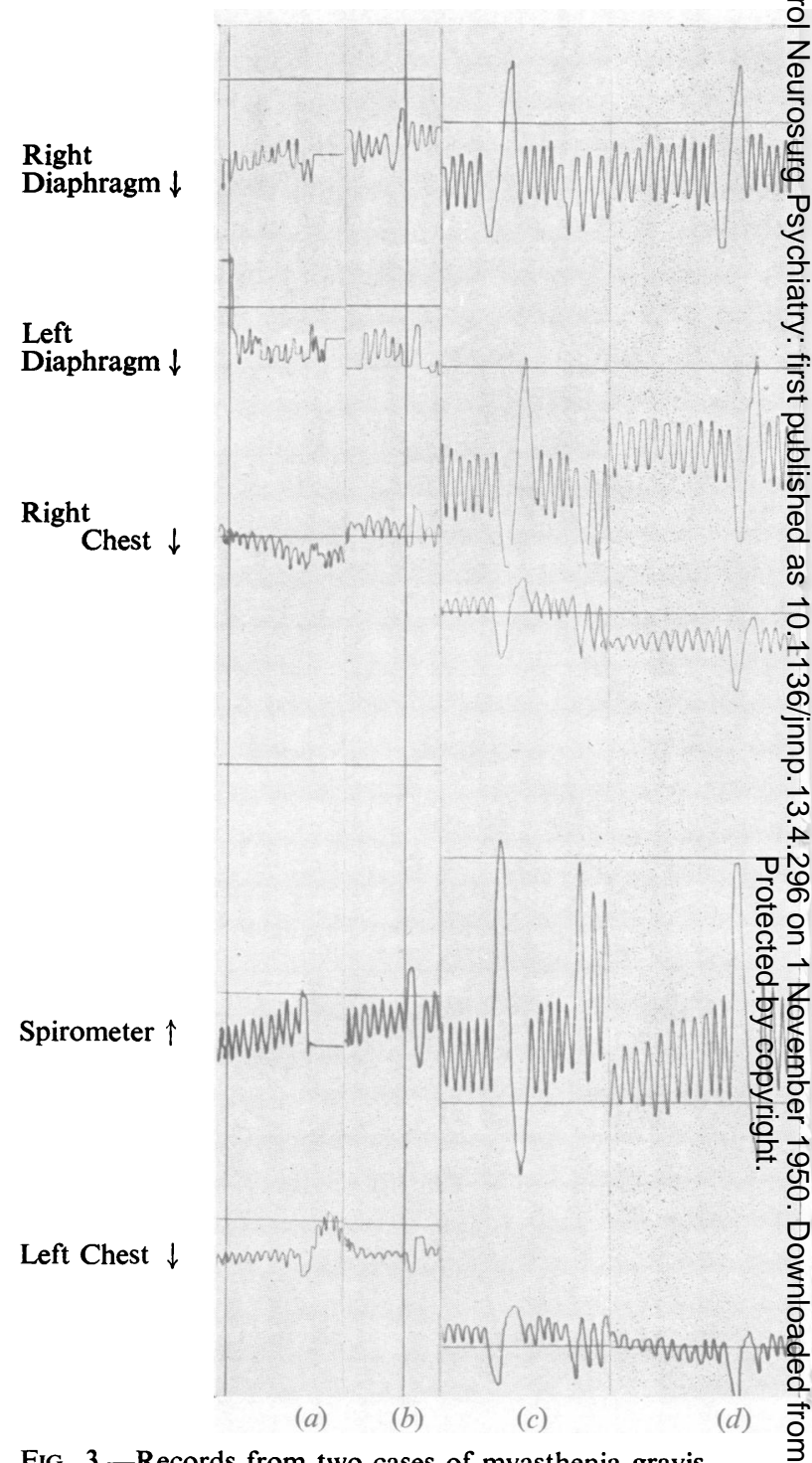

FIG. 3.-Records from two cases of myasthenia gravis.

(a) Case 16. Patient had taken $50 \mathrm{mg}$. prostigmine b mouth two and one-half hours earlier. She had not under? gone thymectomy and the small irregular excursion of the. diaphragm is noted in this record. She was unable to take a deep breath to record vital capacity.

(b) Case 16 fifteen minutes after intravenous prostigmineं, The diaphragm movements are more regular and greatep. in extent.

(c) Case 22. Thymectomy performed four years previously? Normal quiet breathing, vital capacity, voluntary and in voluntary overbreathing are recorded five hours after $30 \mathrm{mg}$ prostigmine by mouth. The excursion of the diaphragm is seen to be as regular as normal and of fair amplitude.

(d) Case 22 ten minutes after intravenous prostigmine.

The arrows point in the direction taken by the penss during inspiration. The vertical line of each square represents $2,300 \mathrm{ml}$. on the spirometer tracing. 


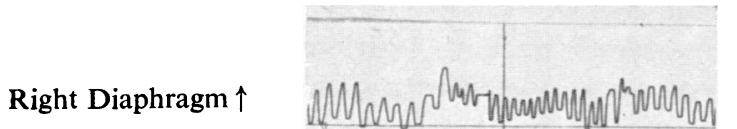

Left Diaphragm $\downarrow$

Right Chest $\downarrow$

Spirometer $\uparrow$

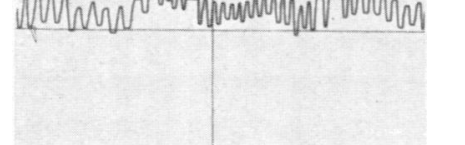

from marked wasting of girdle, limb, and trunk muscles.

A woman with myotonia congenita showed no respiratory abnormality and no satisfactory record of delayed relaxation of the diaphragm to command was obtained during forced breathing.

The one case of progressive lenticular degeneration which was seen showed no involvement of the diaphragm in any involuntary movements although there was a marked unilateral tremor at rest.

A young man with spasmodic torticollis and writer's cramp exhibited no irregular involuntary movement of the respiratory muscles.

A woman suffering from severe dystonia musculorum deformans with accentuation of her symptoms and signs on the right side was examined in the lying position. The respiratory rhythm was wildly irregular but no asymmetry was found between right and left halves of the diaphragm.

Three patients with idiopathic hypoparathyroidism showed no abnormality.

\section{Discussion}

From the observations recorded above it may be seen that certain of the neurological disorders investigated did affect diaphragmatic movement and others did not. The method used in this study for recording expansion of each half of the chest was adequate to show the relative parts played by chest and diaphragm in certain kinds of breathing, and, in general, whether the costal muscles were affected as much as the diaphragm in any particular disorder. It is clear that an abnormality of the diaphragm alone may not be a true indication of the condition of the respiratory muscles as a whole. This has been found in myopathy, and Bergmark (1914) also claimed that he had observed cases of hemiplegia in which the diaphragm moved less on the paralysed side but the costal muscles moved equally well on either side.

Healthy Subjects.-Our measurements of diaphragmatic movement are in agreement with those of previous investigators (Table V).

Although dissection may show the right diaphragm to be " larger and more powerful ", as Dally (1908) states, we cannot agree with his statement that the difference in range of movements between the two sides of the diaphragm (if it exists) is in favour of the right half. We have found it to be invariably in favour of the left side. Since we had two observers working simultaneously, we felt that it was necessary to verify this finding. Our observations have been repeated therefore with observers and tracking devices changed to opposite sides in turn and measurements made of each side separately. Our movement. Involuntary movements interrupted any attempt at overbreathing and the response to a request to take a deep breath was often postponed for several breaths for the same reason.

No marked abnormality of diaphragmatic movement was found in any of the six cases of myopathy which were screened, although they all suffered 
TABLE V

MEASUREMENTS OF DIAPHRAGMATIC MOVEMENT IN HEALTHY INDIVIDUALS GIVEN BY VARIOUS AUTHORS

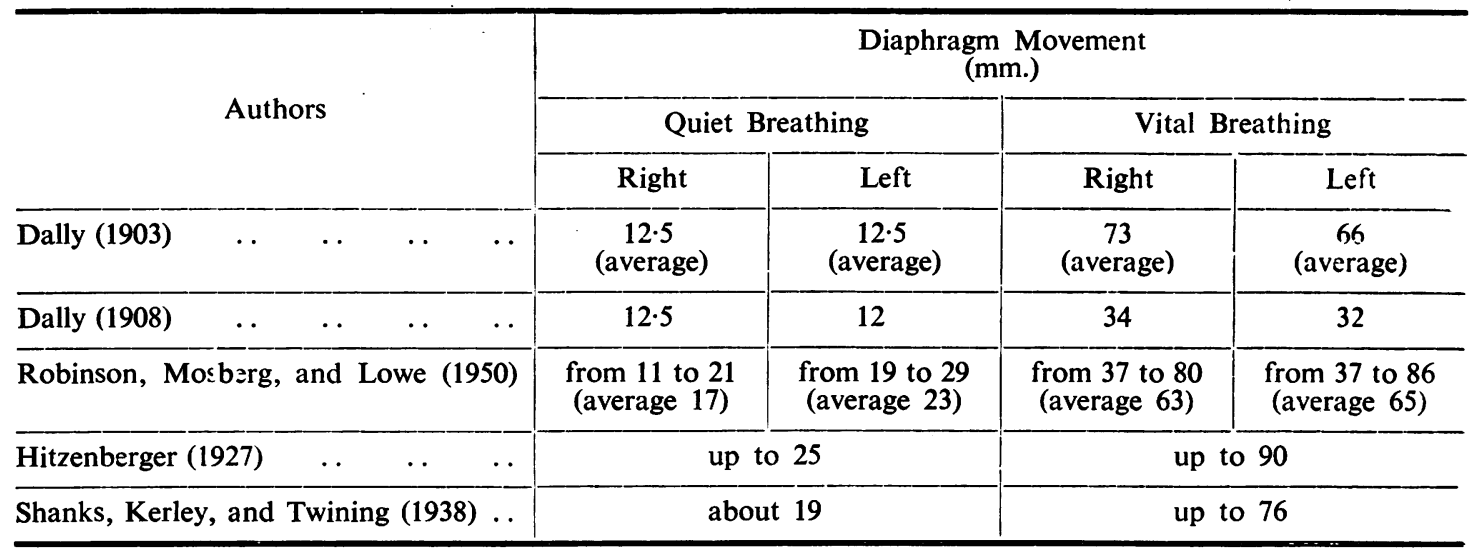

results remain unchanged; and we suggest that the difference between the two sides is due to the fact that the downward movement of the diaphragm on the right side is limited by the liver, whereas the gas bubble in the stomach under the left leaf of the diaphragm offers less resistance.

Our observations of the relative role of chest and diaphragm in various phases of respiration support the theoretical deductions concerning diaphragmatic movement made by Herxheimer (1949) from his records of costal movement. Herxheimer stated also that an increased reserve air indicated a low level diaphragm of good mobility, and two of our records show this.

The elevation of the diaphragm during inspiration, caused by the action of the lower ribs, which was shown in the records made by Gilson and Wade (1950) was seen in one of our cases.

Hemiplegia.-Bergmark (1914) by radiological methods which he does not specify claimed that in seven of his eight cases of residual hemiplegia the movement of the diaphragm on the paralysed side was less. Five of the cases had right-sided paresis and three were left-sided. Hitzenberger (1927) maintains that $x$-ray examination reveals no deviation of diaphragmatic movement from normal in cases of hemiplegia. All the cases described in this series had chronic spastic hemiplegia. Our findings agree most closely with those of Bergmark, as we consider the diaphragm moves less on the paralysed side in forced breathing. The disparity during quiet breathing is modified by the preponderance of the left dome in normal subjects and it would appear that previous writers have paid insufficient attention to this normal inequality. There was no clear correlation between the findings and the site of the pathological process or the extent of the neurological deficit.

Numerous writers (Ross, 1881; Grawitz, 1894 ; Jackson, 1895 ; Oppenheim, 1898 ; Mills, 1898 ; West, 1912; Kolb and Kleyntjens, 1937) have studied chest movements in cases of hemiplegia and arrived at varying conclusions. It is suggested that the costal muscles move less on the hemiplegic side, this being more evident in deep breathing. This agrees with the findings of Kolb and Kleyntjens in chronic spastic hemiplegia. They stated that in this disorder involuntary hyperpnoea induced by inhalation of carbon dioxide produced more movement on the paralysed side. In the present series the records obtained after eliminating the soda-lime canister from the circuit did not confirm this.

Myasthenia Gravis.-Our findings support those expressed by Laszlo and Redlich (1942) who made spirometric studies and took films in quiet and forced inspiration and expiration in five myasthenic patients. Two of these suffered from suffocative attacks in which the vital capacity could not be measured. A prompt rise in the vital capacity of their patients after prostigmine injection was found by these workers. It is clear that measurement of the vital capacity may be a useful guide to the severity of the condition. On the other hand, although those cases whose myasthenia mainly affects the respiratory muscles are benefited a great deal by prostigmine (Cases 16 and 20), some patients with myasthenia will show no great abnormality in the excursion of the diaphragm or the air exchange (Case 19) and yet be incapacitated by severe weakness of the limbs. We consider that the irre gularity of the diaphragmatic movements, observed in the 
patients who had not had thymectomy, was significant. Unfortunately we were unable to examine a patient before and after operation, but as this phenomenon was not observed in any of the patients who had had their thymus gland removed, it would appear to be relevant. It suggests that thymectomy has some beneficial effect on muscle action, and in this case on the diaphragm. This suggestion receives some support from Keynes' statement (1949) that $65 \%$ of his series " have shown a complete or almost complete remission of symptoms" after thymectomy.

Palatal Myoclonus.-Diaphragmatic involvement in this condition has been recorded in the literature. Guillain and Mollaret (1931) reported two cases in which it was demonstrated by fluoroscopic examination. They point out the necessity for repeated examination of the diaphragm in order to find these myoclonic movements and they stress the value of close scrutiny during expiratory apnoea. Riley and Brock (1933) in their review of the literature found seven reports of diaphragmatic myoclonus in 43 cases with myoclonus of the palate, pharynx, and larynx. They appreciated that the diaphragm may not have been examined in many patients, but the few cases found in the literature since 1933 do not appear to make involvement of the diaphragm a common finding in lesions of the central tegmental tract or dentate nucleus.

Lesions of the Cervical Spinal Cord and Phrenic Nerve.-Four of the five cases with clinical evidence of degrees of damage to the cervical spinal cord were found to have various degrees of diaphragmatic palsy (Table IV). It is considered that this method demonstrates a degree of diaphragmatic paresis not suggested clinically nor readily discernible on direct observation of the $x$-ray screen. This may have diagnostic significance and, after repetition, it may acquire prognostic value in such disorders as tumour, amyotrophic lateral sclerosis, and the like. Abnormally low vital capacities were found in these patients. This is of considerable importance when considering the patient's capabilities and also serves as a reminder that such subjects must take special care in avoiding chest infection.

Myopathy.-Our failure to note any marked abnormality of diaphragmatic movement in six cases of myopathy is in agreement with the observations of Sekiya (1940) who stated that in "myopathic muscle atrophy the diaphragm is involved late compared with the ribs", and Hagemann (1937) who recorded free diaphragmatic move- ment in a child with a very severe muscular dystrophy.

Disorders of the Basal Ganglia.-In this group of cases, which caused predominantly one-sided involvement of the limbs and disturbed respiratory rhythm, there was observed no unilateral irregular movements or tremor of the diaphragm.

\section{Summary}

A method of continuous recording is described by means of which a permanent graph may be obtained, representing the simultaneous movement of both leaves of the diaphragm. Groups of patients with different neurological disorders were examined and the findings presented.

A control group of 14 normal males between 25 and 35 years was also investigated. The excursion of the right dome of the diaphragm was found to be constantly less than the left during quiet breathing. This difference was reduced during forced breathing.

Fourteen cases of chronic hemiplegia (eight right-sided and six left-sided) were examined. There was no significant difference between the records of patients with right hemiplegia and those of normal subjects in quiet breathing. In left hemiplegia during quiet respiration the left diaphragm appeared to move less, compared with the right, than in normal subjects. During forced breathing, however, there was a clear tendency towards diminished movement on the paralysed side.

Six cases of myasthenia gravis were examined. The vital capacity may be a useful guide to the severity of the condition and the response to prostigmine of value in prognosis. It is suggested that thymectomy has a beneficial effect on the diaphragm as part of a generalized muscle improvement.

The findings in cases of palatal myoclonus, lesions of the cervical spinal cord and phrenic nerve, Huntington's chorea, myopathy, and certain other neurological disorders are briefly described.

Our grateful thanks are due to Dr. Macdonald Critchley, Dr. J. St. C. Elkington, Dr. L. Guttmann, Dr. J. Purdon Martin, Mr. Wylie McKissock, Dr. W. Ritchie Russell, Sir Charles Symonds, and Dr. F. M. R. Walshe for permission to examine cases under their care. Without the technical assistance of Mr. I. C. Wilson in preparing and maintaining the apparatus this study could not have been carried out. We are greatly indebted to Dr. H. Davies and to the members of the $x$-ray department, National Hospital, Queen Square, for their help in this work.

In particular we wish to thank Dr. E. Arnold Carmichael under whose supervision this study was carried out, and who has given advice and encouragement throughout. 


\section{REFERENCES}

Bergmark, G. (1914). Dtsch. Z. Nervenheilk., 51, 61. Dally, J. F. H. (1903). Lancet, 1, 1800. (1908). Proc. roy. Soc. B, 80, 182.

Gilson, J. C. (1949). Quart. J. Med., 18, 394.

- and Wade, O. L. (1950). Personal communication. Grawitz, E. (1894). Z. Klin. Med., 26, 1.

Guillain, G., and Mollaret, P. (1931). Rev. Neurol., 2, 545.

Hagemann, E. (1937). Mschr. Kinderheilk., 70, 174.

Herxheimer, H. (1949). Thorax, 4, 65.

Hitzenberger, K. (1927). "Das Zwerchfell im gesunden und kranken Zustand." Vienna.

Jackson, J. H. (1895). Lancet, 1, 476.

Kernohan, J. W., Mabon, R. F., Svien, H. J., and Adson, A. W. (1949). Proc. Mayo Clin., 24, 71.

Keynes, G. (1949). Brit. med, J., 2, 611.

Kolb, L. C., and Kleyntjens, F. (1937). Brain, 60, 259.
Laszlo, D., and Redlich, F. C. (1942). Amer. J. med. Sci., 203, 693.

Mills, C. K. (1898). "The Nervous System and its Diseases." Philadelphia.

Oppenheim, H. (1898). "Lehrbuch der Nervenkrankheiten," 2nd ed. Berlin.

Riley, H. A., and Brock, S. (1933). Arch. Neurol. Psychiat., Chicago, 29, 726.

Ross, J. (1881). "Treatise on the Diseases of the Nervous System," vol 2. London.

Sekiya, M. (1940). Orient. J. Dis. Infants, 28, 8.

Shy, G. M., and Carmichael, E. A. (1949). Proc. roy. Soc. Med., 42, 65.

Shanks, S. C., Kerley, P., and Twining, E. W. (1938). "A Textbook of $x$-ray Diagnosis." London.

West, S. (1912). Lancet, 2, 1352.

Wilson, A. B. K., and Walshe, F. M. R. (1950). Proc. roy. Soc. Med., 43, 252. 